\title{
Cockayne syndrome
}

INSERM

\section{Source}

INSERM. (1999). Orphanet: an online rare disease and orphan drug data base. Cockayne syndrome. ORPHA:191

Cockayne syndrome (CS) is a multisystem condition characterized by short stature, a characteristic facial appearance, premature aging, photosensitivity, prog ressive neurological dysfunction, and intellectual deficit. 